\section{Pressure volume characteristics of the lungs in sudden infant death syndrome}

Sir,

We share the disappointment of Fagan and Milner ${ }^{1}$ in their inability to find any difference in the pressure/volume relations of lungs from SIDS victims and controls, particularly as we have recently published ${ }^{23}$ a hypothesis on Sudden Infant Lung Collapse (SILC) syndrome in which surfactant malfunction is an important component! We offer the following comments, which may have some bearing on the problem.

Fagan ${ }^{4}$ pointed out in 1976 that the recoil of the lung is dominated by tissue forces at high lung volume and by surface tension at low volume. Therefore, if some examples of SIDS are related to abnormal surface tension rather than abnormal tissue forces maximal inflation volume need not concern us further.

Moreover, the lowest volume for which figures are given would approximate in vivo to functional residual capacity, a volume that is too high for initiation of collapse phenomena. The. low pressure at which this volume remained, however, may be explained by previous studies showing that the rate of lung collapse is very temperature sensitive near body temperature below which the film is much more rigid and collapse rate considerably reduced. Fagan $^{4}$ originally reported that their measurements were made at room temperature, and consequently any defect in performance of surfactant in SIDS cases (should it exist) could have been hidden by their methodology. Should Fagan and Milner extend their technique further, observations of opening behaviour at $37^{\circ} \mathrm{C}$ may be more revealing.

In conclusion, the analysis presented by Fagan and Milner shows that there is probably no difference in tissue mechanics between SIDS and controls (high volume results), but it is not possible to judge the situation regarding a possible defect in lung surfactant, particularly if, as described in the original methodology, ${ }^{4}$ 'any lung that failed to open completely ... was excluded from the series'. Further post mortem investigations at body temperature and at lower lung volumes must be performed to resolve the important questions raised as a result of this present study.

D P Southall and D G Talbert The Cardiothoracic Institute, London SW3 6MP

\section{Dr Fagan and Professor Milner comment:}

We are grateful for the interest of Drs Southall and Talbert in our paper. ${ }^{1}$ We have re-examined our data in the light of their letter.
(1) Table Air volume at distending pressure of $O$ and $1 \mathrm{~cm} \mathrm{H}_{2} \mathrm{O}$ for SIDS and control babies

\begin{tabular}{|c|c|c|c|c|}
\hline & \multicolumn{2}{|c|}{$\begin{array}{l}\text { Air volume at distending } \\
\text { pressure of } 1 \mathrm{~cm} \mathrm{H}_{2} \mathrm{O} \\
\text { as } \% \text { of volume at a } \\
\text { pressure of } 30 \mathrm{~cm} \mathrm{H}_{2} \mathrm{O}\end{array}$} & \multicolumn{2}{|c|}{$\begin{array}{l}\text { Air volume at zero distending } \\
\text { pressure as } \% \text { of volume at a } \\
\text { pressure of } 30 \mathrm{~cm} \mathrm{H}_{2} \mathrm{O}\end{array}$} \\
\hline & No & Mean $(S D)$ & No & Mean $(S D)$ \\
\hline \multirow{2}{*}{$\begin{array}{l}\text { SIDS } \\
\text { babies } \\
\text { Control } \\
\text { babies }\end{array}$} & $20 / 23$ & $35 \cdot 2(7 \cdot 9)$ & $17 / 23$ & $22 \cdot 2(7 \cdot 9)$ \\
\hline & $8 / 17$ & $36 \cdot 6(5 \cdot 7)$ & $13 / 17$ & $22 \cdot 0(6 \cdot 2)$ \\
\hline
\end{tabular}

Thus there is clearly no significant difference between the two groups and one third of the total lung volume remains with a distending pressure of only $1 \mathrm{~cm} \mathrm{H}_{2} \mathrm{O}$. We consider these data provide no evidence to suggest alveolar collapse is occurring at low lung volumes.

(2) Time and temperature effects. Time and temperature controls were carried out, ${ }^{5}$ and it was found that the alteration between successive inflations carried out at $+37^{\circ} \mathrm{C}$ or room temperature, or room temperature and $+37^{\circ} \mathrm{C}$, were the same as between two successive inflations at either temperature. That is, the major source of variation between inflation cycles was whether it was the 1st, 2nd, or 3rd cycle rather than whether at room temperature or $+37^{\circ} \mathrm{C}$. In this study the 2nd cycle at room temperature was taken as the index cycle.

For this letter, the differences between 1st and 2 nd cycle were re-examined at a distending pressure of $5 \mathrm{~cm} \mathrm{H}_{2} \mathrm{O}$. Cot deaths: $\mathrm{No}=23$ Variation between 1 st and 2nd cycle $=2 \cdot 3 \%($ SD $1 \cdot 1 \%)$

Normals: $\mathrm{No}=17$ Variation between 1 st and 2nd cycle $=2.3 \%($ SD $3 \cdot 6 \%)$.

Gruenwald $^{6}$ suggested that repeated cycling of the lung could be a method of assessing the amount/efficacy of the surfactant reservoir, and in the course of this investigation several lungs were repeatedly cycled on two or three occasions after several days storage at $+4^{\circ} \mathrm{C}$ between cycles. The effects shown, ${ }^{5}$ and current re-examination, were identical between SIDS and others. These data show that the results were not biased by temperature factors.

(3) Lung opening pressures. In our hands this was not a viable experimental procedure using post mortem material as it was found that attempts to degas the lungs of infants beyond the neonatal period led to lung rupture. All the SIDS lungs contained air at the outset of the 1st volumepressure loop and so, as expected, all opened at far lower pressures than degassed neonatal lungs.

Finally, we are sceptical that the information published by Southall $e t a^{3}$ supports the concept that alveolar collapse is occurring in babies with recurrent cyanotic attacks.

\section{References}

${ }^{1}$ Fagan DG, Milner AD. Pressure volume characteristics of the 
lungs in sudden infant death syndrome. Arch Dis Child 1985:60:471-3.

2 Talbert DG, Southall DP. A bimodal form of alveolar behaviour induced by a defect in lung surfactant-a possible mechanism for sudden infant death syndrome. Lancet 1985;i:1330.

${ }^{3}$ Southall DP, Talbert DG, Johnson P, et al. Prolonged expiratory apnoea: a disorder resulting in episodes of severe arterial hypoxaemia in infants and young children. Lancet 1985;ii:571-7.

${ }^{4}$ Fagan DG. Post mortem studies of the semistatic volumepressure characteristics of infants lungs. Thorax 1976;31:534-43.

5 Fagan DG. Developmental and pathological studies of the structure and function of the lung in children. (Thesis). Cambridge University, 1973:26-37.

${ }^{6}$ Gruenwald P. The effect of age on surface properties of excised lungs. Proc Soc Exp Biol Med 1966;122:388-92.

\section{Treatment for renovascular hypertension}

Sir,

We read with interest the report of Awazu et al ${ }^{1}$ that expands the experience with percutaneous transluminal balloon angioplasty (TLA) in children. We recently reported 17 children with renovascular hypertension, ${ }^{2}$ seven of whom were treated with this technique since 1979. Cure (defined as normotensive for age with no drugs) was achieved in two patients with main renal artery lesions for which TLA is probably best suited. Two patients developed renal artery thrombosis after the procedure, one of whom was successfully treated by autotransplantation of the kidney to the ipsilateral iliac fossa.

Enthusiasm for angioplasty must therefore be tempered by proper selection of patients and restriction of the technique to centres where experienced radiologists and surgeons are available. Two out of the five patients in Awazu's series still required treatment with antihypertensive agents. As cure is preferable to chronic drug treatment, surgical techniques such as vascular repair or autotransplantation should be considered. Transluminal balloon angioplasty is a welcome addition to the available treatment modalities for these rare patients, but its exact role requires further careful assessment and documentation.

\section{References}

${ }^{1}$ Awazu M, Shimizu M, Hojo H, Osano M, Kohda E. Percutaneous transluminal angioplasty for renovascular hypertension. Arch Dis Child 1985;60:627-30.

2 Watson AR, Balfe JW, Hardy BE. Renovascular hypertension in childhood: a changing perspective in management. $J$ Pediatr 1985;106:366-72.

\section{A R Watson City Hospital, Nottingham NG5 $1 P B$ AND J W Balfe Hospital for Sick Children, Toronto}

Dr Awazu and co-workers comment:

We agree with Drs Watson and Balfe's comment on restriction of angioplasty to certain centres and the proper selection of patients. With experienced staff and a special observance for the possible side effects, we have not experienced any complications up to the present, though the number of the patients is small. Also we think that the proper selection of the patients is an essential factor for treatment with angioplasty. In our study three out of five patients were cured (as defined by Drs Watson and Balfe). In their study two out of five patients (two out of seven patients who developed thrombosis are impossible to assess) were technically not feasible, so it is difficult to say that they were properly selected. Therefore two out of three remaining patients were cured. Those ratios are encouraging.

As for the two patients in our study who required antihypertensive drugs, it might be necessary to consider surgery in the future. One patient had bilateral disease, however, in whom it would be difficult to expect cure with surgical treatment, as the two patients with bilateral disease who underwent autotransplantation clearly show. Considering the younger age of the patients and the possible extension or multiple occurrence of the lesion in the future, our present treatment is justified. Also the repeatability and the relative non-invasiveness of angioplasty should be re-evaluated.

\section{Copper and the preterm infant}

Sir,

We have read with interest the recent report by Sutton $e t$ $a l^{1}$ of copper deficiency in four very low birthweight infants. ${ }^{1}$ These authors found that diagnosis was made more difficult because of the lack of a suitable reference range for copper for these infants. The studies quoted by Sutton et al provide limited data on serum trace metal concentrations in preterm infants up to 1981 . In 1983 we reported serial serum copper and zinc concentrations in a group of 48 preterm infants during the first year of life. ${ }^{2} \mathrm{~A}$ comparison of the results for plasma copper determinations obtained in Glasgow and serum copper concentrations in Belfast adjusted to show the geometric mean is shown in the Table. It is reassuring to find such good agreement between these two studies.

Sutton et al suggest that very low birthweight infants should be given at least $1 \mu \mathrm{mol}(6 \cdot 4 \mu \mathrm{g} / 100 \mathrm{ml})$ of copper $/ \mathrm{kg} /$ day during parenteral and enteral feeding. Our own findings suggest that this statement may be unwarranted. Our policy is to provide $0.3 \mu \mathrm{mol}(1.9 \mu \mathrm{g} / 100 \mathrm{ml})$ of copper $/ \mathrm{kg}$ daily for very low birthweight infants who are receiving parenteral nutrition. ${ }^{3}$ The last seven infants of $<30$ weeks' gestation (mean gestation 27 weeks, mean birthweight $930 \mathrm{~g}$ ) had serum copper concentrations checked at a mean postnatal age of 70 days (mean and median post-conceptional age 37 weeks). None had a serum copper concentration outside the $95 \%$ ranges for the Belfast and Glasgow infants. For the group as a whole mean serum copper concentration was $11.5 \mu \mathrm{mol} / \mathrm{l}$ (73 $\mu \mathrm{g} / 100 \mathrm{ml}$ ) (range 6.6-14.8). Furthermore, as copper is excreted by the biliary system high serum concentrations may occur in preterm babies with cholestasis. ${ }^{4}$ Thus, 